\title{
Genetic Variation among Sorghum (Sorghum bicolor L. Moench) Landraces from Eritrea under Post-Flowering Drought Stress Conditions
}

\author{
Tesfamichael Abraha1,2*, Stephen Mwangi Githiri², Remmy Kasili², Woldeamlak Araia ${ }^{1}$, \\ Aggrey Bernard Nyende ${ }^{2}$ \\ ${ }^{1}$ Hamelmalo Agricultural College (HAC), Keren, Eritrea \\ 2Jomo Kenyatta University of Agriculture and Technology (JKUAT), Institute of Biotechnology Research, Nairobi, \\ Kenya \\ Email: ${ }^{*}$ tesfanigl@yahoo.com
}

Received 3 April 2015; accepted 13 June 2015; published 16 June 2015

Copyright (C) 2015 by authors and Scientific Research Publishing Inc.

This work is licensed under the Creative Commons Attribution International License (CC BY). http://creativecommons.org/licenses/by/4.0/

(c) (i) Open Access

\section{Abstract}

Sorghum (Sorghum bicolour (L.) Moench) grown under rain-fed conditions is usually affected by drought stress at different stages, resulting in reduced yield. The assessment of variation in morpho-physiological traits contributing towards drought tolerance at these stages is of vital importance. This study was conducted using a split plot design with three replications to evaluate 25 sorghum accessions at post flowering stage under well watered and drought stress conditions at Hamelmalo Agricultural College. The data of 14 different morpho-physiological traits were subjected to analysis of variance, estimation of genetic variability and heritability and principal component analysis. We analyzed variance for seedling vigor, number of leaves, leaf area, stay-green, peduncle exsertion, panicle length and width, plant height, days to flowering and maturity, grain yield, biomass and harvest index under drought stress and irrigated conditions. The results showed that genotypic differences were significant at $\mathrm{P}<0.05-<0.001$. High magnitude of phenotypic and genotypic coefficient of variations for plant height, harvest index and biomass as well as high heritability for days to flowering, panicle length, days to maturity and over all agronomic score were recorded. Principal component (PC) analysis showed that the first 4 PCs had Eigen value $>1$ explaining $74.6 \%$ of the total variation with grain yield, biomass, stay-green, leaf area, peduncle exsertion and days to flowering and maturity being the most important characters in PC1 and PC2. This research demonstrated high diversity for the characters studied. Moreover, the result showed that drought stress reduced the yield of some genotypes, though others were tolerant to drought. Accessions EG 885, EG 469, EG 481, EG 849, Hamelmalo, EG 836 and EG 711 were

\footnotetext{
"Corresponding author.
} 
identified as superior for post-flowering drought tolerance and could be used by breeders in improvement programs.

\author{
Keywords
}

Drought Tolerance, Genetic Variability, Post Flowering, Principal Component Analysis, Sorghum

\title{
1. Introduction
}

Sorghum (Sorghum bicolour (L.) Moench) is the fifth most important cereal crop worldwide after wheat (Triticum aestivum), rice (Oryza sativa), maize (Zea mays) and barley (Hordeum vulgare). It forms the most important dryland cereal crop for the semi-arid tropics together with maize and pearl millet (Pennisetum glaucum (L.). It is grown in at least 86 countries, in an area of 38 million hectares and with annual grain production of about 58 million tonnes. The average productivity reaches $1.5 \mathrm{t} \cdot \mathrm{ha}^{-1}[1]$.

Drought tolerance is defined as the relative yield of a genotype compared with other genotypes subjected to the same drought stress [2]. Drought susceptibility of a genotype is often measured as a function of the reduction in yield under drought stress [3], while the values are confounded with the differential yield potentials of genotypes [4]. Enhancing drought tolerance is an important objective in many crop improvement programs. Drought tolerance is a complex trait controlled by many genes, and is dependent on the timing and severity of moisture stress. It is one of the most-difficult traits to study and characterize [5].

Although sorghum has an ability to cope with many types of stresses, including heat, drought, salinity and flooding [6], in arid and semi-arid regions, this crop is usually affected by drought stress at the post flowering stage of growth [5] [7]. Drought tolerance in sorghum is a complex trait influenced by many genes coding for various traits contributing towards tolerance [8]. The crop can be affected if the drought stress is imposed at any one of the following stages: early vegetative stage, period of panicle development prior to flowering, and from pollination to maturity, post-flowering [9]. Post-flowering drought stress in particular can result in significant reductions in crop yield [10].

Stay-green or non-senescence is an important trait associated with drought tolerance [11]. Stay-green trait is the ability of the plant to retain greenness during grain ripening under water limited conditions [12]. Sorghum genotypes with the stay-green trait continue to fill their grains normally even under limited water or drought stress conditions [13]. Genetic variability for agronomic characters is also a key component of breeding programs for broadening the gene pool of crops [14]. Success in breeding under drought stress conditions depends on understanding the genetic basis of drought tolerance in crop plants based on various morpho-physiological traits [15]. Knowledge of heritability influences the choice of selection procedures used by the plant breeder to decide which selection methods would be the most useful to improve the character, to predict gain from selection and to determine the relative importance of genetic effects [16] [17]. Evaluations of the components of variation and heritability are therefore among characters that will facilitate improvement of crops such as sorghum.

The objectives of this research were: 1 ) to evaluate sorghum landraces for variation in morpho-agronomical traits under managed drought stress conditions in Eritrea; 2) to assess the associations among morpho-agronomical traits recorded on sorghum landraces under managed drought stress conditions.

\section{Materials and Methods}

\subsection{Plant Materials and Trial Site}

The germplasm used in this study comprised of 25 sorghum genotypes including 21 accessions selected from 2013 rapid screening experiment, one improved line (B-35) from ICRISAT, one improved variety (Hamelmalo) from the Eritrean Sorghum Improvement Program, and two susceptible accessions from the Eritrean Gene Bank (Table 1).

The experiment was conducted under managed drought stress conditions at Hamelmalo Agricultural College (HAC) farm from March-June, 2014 dry season period. Geographically the trial site is located at $15^{\circ} 52^{\prime} 15^{\prime \prime N}$ latitude and $38^{\circ} 27^{\prime} 55^{\prime \prime} \mathrm{E}$ longitudes with an altitude of 1274 meters above sea level in a semi-arid agro-ecological 
Table 1. Twenty five sorghum genotypes used in this study along with their sources, names and status.

\begin{tabular}{|c|c|c|c|c|}
\hline S. No. & Germplasm identifier & Area of collection (administration region) & Local name & Status \\
\hline 1 & EG 469 & Gash Barka & Tseda Bazenay & Landrace \\
\hline 2 & EG 849 & Gash Barka & Hugurtay & Landrace \\
\hline 3 & EG 537 & South & Anseba & Landrace \\
\hline 4 & Hamelmalo & Anseba and Gash Barka & Hamelmalo & Improved cultivar \\
\hline 5 & EG 806 & Gash Barka & Hiriray & Landrace \\
\hline 6 & EG 782 & South & Tseda Hele & Landrace \\
\hline 7 & EG 797 & Gash Barka & Wedi-Aker & Landrace \\
\hline 8 & EG 791 & Gash Barka & Korekora & Landrace \\
\hline 9 & EG 815 & Gash Barka & Estif & Landrace \\
\hline 10 & EG 836 & Anseba & Hugurtay & Landrace \\
\hline 11 & EG 883 & Gash Barka & Kinabiba & Landrace \\
\hline 12 & EG 885 & Gash Barka & Duruta & Landrace \\
\hline 13 & EG 889 & Gash Barka & Kileaentu & Landrace \\
\hline 14 & EG 1224 & Gash Barka & Mahagen & Landrace \\
\hline 15 & EG 526 & Anseba & Wedi-Aker (Short) & Landrace \\
\hline 16 & EG 711 & Anseba & Embulbul & Landrace \\
\hline 17 & EG 783 & Gash Barka & Aklamoy & Landrace \\
\hline 18 & EG 813 & Anseba & Wedi-Ferej & Landrace \\
\hline 19 & EG 830 & Gash Barka & Wedi-Arba & Landrace \\
\hline 20 & EG 481 & Anseba & Wedi-Susa & Landrace \\
\hline 21 & H-35-1 & South & Tseda Mashela & Landrace \\
\hline 22 & B-35 & ICRISAT & B-35 & Improved cultivar \\
\hline 23 & EG $870(S)$ & Gash Barka & Ajebsidu & Landrace \\
\hline 24 & EG $473(S)$ & South & Keih Hele & Landrace \\
\hline 25 & EG 843 (S) & South & Koden & Landrace \\
\hline
\end{tabular}

where, $\mathrm{S}$ = Susceptible.

zone of Eritrea. The research area is located $12 \mathrm{~km}$ away from Keren city towards the north on the Keren-Nakfa road, along the Anseba River in Anseba region. The soil type of the experimental site was sandy clay loam with an average maximum and minimum air temperatures during the experimental period reached $38^{\circ} \mathrm{C}$ and $20^{\circ} \mathrm{C}$ respectively. Soil moisture content before sowing and after imposing stress were taken.

\subsection{Experimental Design and Treatments}

A split plot design was used by setting two main plots, fully irrigated and stress plots with three replications. The spacing between the irrigated and stressed replications was three meters. The sub plots were the 25 genotypes that were planted in plots of four rows with a spacing of $75 \mathrm{~cm} \times 20 \mathrm{~cm}$ between and within rows respectively and three meter row length. Soil moisture content before sowing and after imposing stress were taken.

In order to impose drought stress, the accessions were subjected to two conditions: non-stressed (with normal irrigation) and drought stressed (irrigation withheld) at reproductive phase. All the accessions in both irrigated 
and stress treatments were fully irrigated until booting to early flowering stage. At flowering stage water was withheld for 14 days for the drought stress treatment, while the control treatment received regular irrigation throughout the experiment. Normal watering was resumed when the flowered plants showed visual signs of wilting. Soil moisture was measured by the department of land resources and environment of Hamelmalo Agricultural College twice in both the stress and control treatments at the time of water being withheld and before the water stress was relieved.

\subsection{Phenotypic Data Recorded}

The phenotypic data (Table 2) were recorded during crop growth.

\subsection{Statistical Analysis}

\subsubsection{Analysis of Variance (ANOVA)}

Data on the various morpho-agronomical traits were analyzed using the Genstat 14 Statistical software [20]. In addition principal component analysis (PCA) was conducted after standardization to mean of zero and variance of one. Cluster analysis was done using the Unweighted Pair Group Method with Arithmetic Mean (UPGMA) analysis [21] and dendrograms were constructed using the SAHN program.

\subsubsection{Analysis of Genetic Variability and Estimation of Coefficients of Variations}

Genotypic and phenotypic variability were estimated using the methods illustrated by [22]. In order to identify the major traits contributing to the overall phenotypic variation among the germplasm accessions and to estimate the

Table 2. Full names, abbreviations and descriptions of the traits investigated in this study.

\begin{tabular}{|c|c|c|c|}
\hline S. No & Traits name & Abbreviations & Description \\
\hline 1 & Seedling vigor & SV & Visual observation of the seedling in 1 - 5 scale where 1 poor and 5 highly vigor \\
\hline 2 & Days to $50 \%$ flowering & DFL & $\begin{array}{l}\text { The date when } 50 \text { percent of the plants produced flowers was recorded and } \\
\text { converted in number of days from date of planting up to date of heading }\end{array}$ \\
\hline 3 & Plant height & PLHT & $\begin{array}{l}\text { Height of the plant from the base of the plant to the tip of the panicle in } \mathrm{cm} \text { at } \\
\text { maturity }\end{array}$ \\
\hline 4 & Total number of leaves & TNOL & Number of leaves on the main plant stem \\
\hline 5 & Leaf area & LA & $\begin{array}{l}\text { Measurement of leaves }\left(\mathrm{cm}^{2}\right) \text { using LI } 3000 \text { C Portable area meter from } 5 \\
\text { randomly selected plants in each replication during early morning hours when } \\
\text { leaves were fully turgid }\end{array}$ \\
\hline 6 & Stay green & StG & $\begin{array}{l}\text { Stay-green scores at maturity based on visual ratings [18] using } 1 \text { to } 5 \text { scale }(1 \leq \\
10 \% \text { leaves stay green and } 5=>75 \% \text { leaves stay green and most desirable) }\end{array}$ \\
\hline 7 & Peduncle exsertion & PEX & $\begin{array}{l}\text { The average length of the node between the flag leaf and the base of the panicle } \\
\text { measured in cm from } 5 \text { randomly selected plants at maturity then ranked by their } \\
\text { values }\end{array}$ \\
\hline 8 & Panicle length & PL & $\begin{array}{l}\text { Panicle length measurement }(\mathrm{cm}) \text { from the base of the panicle to the tip from five } \\
\text { randomly selected plants per plot at maturity }\end{array}$ \\
\hline 9 & Panicle width & PW & $\begin{array}{l}\text { Panicle width measurement in the widest diameter of the panicle on five } \\
\text { randomly selected plants per plot at maturity }\end{array}$ \\
\hline 10 & Days to maturity & $\mathrm{DM}$ & $\begin{array}{l}\text { The date when } 90 \text { percent of the plants are physiologically mature counting in } \\
\text { days taken from planting up to physiological maturity }\end{array}$ \\
\hline 11 & $\begin{array}{l}\text { Over all plant } \\
\text { agronomic score }\end{array}$ & OAS & Over all plant agronomic scores ( 5 = most desirable and $1=$ least desirable) [19] \\
\hline 12 & Grain weight & GW & $\begin{array}{l}\text { Total grain weight per plot }(\mathrm{kg}) \text { after threshing then converted into tons per } \\
\text { hectare }\end{array}$ \\
\hline 13 & Biomass & $\mathrm{BM}$ & $\begin{array}{l}\text { The total weight of the plants in the two middle rows (Kg), } 15 \text { plants/row then } \\
\text { averaged value }\end{array}$ \\
\hline 14 & Harvest index & $\mathrm{HI}$ & $\begin{array}{l}\text { The ratio of grain weight to the total biomass (\%) computed from the two middle } \\
\text { rows then taken average value }\end{array}$ \\
\hline
\end{tabular}


broad sense heritability, cluster and principal component analysis for the various morph-physiological traits in sorghum under water stress and control condition were analyzed using the following formulae:

1. Genotypic variance, $G V=(M S g-M S e) / r$, where $M S g$ = mean square of genotypes, $M S e=$ mean square of error, and $r=$ number of replications;

2. Phenotypic variance, $P V=G V+M S e$, where $G V=$ genotypic variance and $M S e=$ mean square of error;

3. Phenotypic coefficient of variation, $P C V=\sqrt{(P V) / \bar{x}} \times 100$, where $P V=$ phenotypic variance and $\bar{x}=$ mean of the character;

4. Genotypic coefficient of variation, $G C V=\sqrt{(G V) / \bar{x}} \times 100$, where $G V=$ genotypic variance and $\bar{x}=$ mean of the character;

5. Heritability (broad sense heritability), $H=G V / P V$, where $G V$ and $P V$ are genotypic and phenotypic variances respectively.

\section{Result and Discussion}

\subsection{Assessment of Morpho-Physiological Traits}

The mean values for the panicle related traits such as peduncle exsertion, (PEX), panicle length (PL) and panicle width (PW) showed significant reduction under the drought stress conditions. With regard to PEX, the mean values ranged from 3.3 to $12.3 \mathrm{~cm}$ scored by Hamelmalo and EG 711 accessions under drought stress conditions respectively (Table 3). In the fully irrigated condition, the range was 4.3 to 18.3 which recorded by Hamelmalo and EG 526 respectively. There were no significant differences recorded among the accessions for panicle width (PW) under the fully irrigated conditions, while there were highly significant differences under the drought stress conditions. Under drought stress conditions the values for PW ranged from 5 to $9.3 \mathrm{~cm}$ in EG 889, EG 797 and EG 469 respectively. Panicle length (PL) was slightly fluctuated between the stressed and irrigated accessions because some accessions such EG 791, EG 883, EG 889, EG 711 and EG 843 perform better under drought stress condition than under fully irrigated condition. Genotype EG 469 scored the highest PL (28 cm) and lowest by EG $836(9 \mathrm{~cm})$ under drought stress condition. With regard to productive tillers EG 526, EG783 and EG 870 accessions scored highest tillering capacity under stress condition and lowest by EG 469, EG 849 and EG 481 (data not shown in table).

Leaf area had a significant role in drought tolerance evaluations in sorghum. In the current study accessions with medium value of leaf area exhibited higher yield. Accessions EG $849\left(269.3 \mathrm{~cm}^{2}\right)$, Hamelmalo $\left(285.7 \mathrm{~cm}^{2}\right)$, EG $836\left(262 \mathrm{~cm}^{2}\right)$, EG $885\left(216 \mathrm{~cm}^{2}\right)$ and EG $469\left(285 \mathrm{~cm}^{2}\right)$ recorded medium value of leaf area and with good yield attributes. However, few accessions such as EG $481\left(195.3 \mathrm{~cm}^{2}\right)$, EG $711\left(176.7 \mathrm{~cm}^{2}\right)$ and B-35-1 (174.3 $\mathrm{cm}^{2}$ ) were observed to have lower leaf area but scored high yields (Table 3). Under drought conditions optimum leaf area (LA) is important for optimum photosynthetic activity. The genotype Hamelmalo with $433.3 \mathrm{~cm}^{2}$ gave the highest leaf area under irrigation while it reduced its leaf area to $285.7 \mathrm{~cm}^{2}$ under drought stress conditions. In agreement with the current study, drought tolerance in sorghum is associated with smaller leaf area [23]. This indicated that drought considerably reduced leaf area in this genotype to save loss of water through evapo-transpiration. However, such reduced leaf area may cause lower photosynthetic activity which is also unwanted [24]. Moreover, traits like reduced leaf area and prolonged stomata closure, decrease water loss, which in turn result in reduced dry matter production and therefore, reduced final yield [25]. Hence, optimum leaf area is important for producing high dry matter as well as grain yield under water stressed situations.

The genotypes tested also showed significant difference among each other with regard to stay-green. Overall performance of the sorghum genotypes indicated that stay-green score ranged from 2.0 to 4.7 (mean 3.3; SE + 0.50). Among the controls, B-35 showed an average score of 3.3 whereas EG 836, EG 883 and EG 885 scored the highest stay-green value with 4.7, 4.3 and 4.3 respectively. Among the genotypes evaluated, 16 recorded stay-green scores more than or equal to the mean and 9 of them had score less than the mean. Five promising genotypes EG 469, EG 489, Hamelmalo, EG 836 and EG 711 were identified on the basis of their stay-green score that are associated with higher yield attribute medium flowering dates and overall agronomic desirability in this trial.

Significant effects of genotypes were recorded for plant height (PLHT), days to 50\% flowering (DFL), days to maturity (DM), overall agronomic score (OAS), grain yield (GY), and total biomass (BM) under both treat- 
Table 3. Mean genotype values for leaf related traits, panicle width and length under drought stress (Str) and control (Con) conditions, Hamelmalo Agricultural College.

\begin{tabular}{|c|c|c|c|c|c|c|c|c|c|c|c|c|}
\hline \multirow{2}{*}{ Genotype } & \multicolumn{2}{|c|}{ LA } & \multicolumn{2}{|c|}{ NoL } & \multicolumn{2}{|c|}{ STG } & \multicolumn{2}{|c|}{ PEX } & \multicolumn{2}{|c|}{$\mathrm{PaW}$} & \multicolumn{2}{|c|}{$\mathrm{PaL}$} \\
\hline & Con & Str & Con & Str & Con & Str & Con & Str & Con & Str & Con & Str \\
\hline EG 469 & 361.7 & 285.0 & 11.3 & 10.3 & - & 4.0 & 9.7 & 6.3 & 13.3 & 9.3 & 29.3 & 28.0 \\
\hline EG 849 & 289.0 & 269.3 & 10.3 & 11.0 & - & 4.3 & 9.7 & 7.3 & 11.3 & 8.7 & 14.0 & 12.7 \\
\hline EG 537 & 301.7 & 253.0 & 12.3 & 12.3 & - & 3.0 & 14.7 & 7.7 & 9.3 & 8.3 & 28.3 & 24.7 \\
\hline Hamelmaloo & 433.3 & 285.7 & 12.0 & 12.0 & - & 4.0 & 4.3 & 3.3 & 7.7 & 6.0 & 20.7 & 19.7 \\
\hline EG 806 & 205.0 & 191.0 & 10.0 & 9.7 & - & 3.0 & 12.0 & 9.7 & 11.0 & 7.3 & 14.0 & 11.7 \\
\hline EG 782 & 206.0 & 191.3 & 11.3 & 10.3 & - & 3.3 & 12.3 & 9.3 & 14.0 & 8.3 & 15.3 & 14.0 \\
\hline EG 797 & 295.7 & 267.7 & 10.0 & 10.0 & - & 2.7 & 13.3 & 5.7 & 8.3 & 5.0 & 19.3 & 17.3 \\
\hline EG 791 & 293.3 & 266.7 & 10.3 & 10.3 & - & 3.7 & 13.7 & 9.0 & 9.0 & 6.7 & 21.3 & 21.7 \\
\hline EG 815 & 279.7 & 262.3 & 10.0 & 9.7 & - & 2.0 & 10.7 & 4.7 & 10.0 & 6.0 & 22.3 & 22.3 \\
\hline EG 836 & 270.0 & 243.3 & 11.3 & 10.3 & - & 4.7 & 12.0 & 7.0 & 9.7 & 6.3 & 10.7 & 9.0 \\
\hline EG 883 & 358.0 & 323.7 & 11.3 & 11.7 & - & 4.3 & 13.0 & 9.7 & 9.3 & 8.0 & 17.0 & 19.3 \\
\hline EG 885 & 233.7 & 216.0 & 11.0 & 10.7 & - & 4.3 & 11.0 & 7.3 & 9.3 & 6.3 & 11.0 & 10.7 \\
\hline EG 889 & 224.7 & 214.7 & 11.3 & 10.0 & - & 3.0 & 15.7 & 8.3 & 6.7 & 5.0 & 24.0 & 29.7 \\
\hline EG 1224 & 218.7 & 205.3 & 9.3 & 10.0 & - & 2.7 & 11.3 & 6.7 & 10.0 & 5.7 & 24.7 & 17.3 \\
\hline EG 526 & 199.7 & 196.0 & 10.0 & 9.0 & - & 3.7 & 18.3 & 10.7 & 10.7 & 5.7 & 23.0 & 20.0 \\
\hline EG 711 & 197.0 & 176.7 & 9.7 & 10.0 & - & 4.0 & 15.7 & 12.3 & 8.0 & 7.0 & 9.7 & 13.3 \\
\hline EG 783 & 303.7 & 236.3 & 12.3 & 11.0 & - & 3.3 & 10.0 & 6.3 & 11.0 & 6.0 & 9.7 & 10.0 \\
\hline EG 813 & 198.3 & 180.0 & 10.0 & 10.0 & - & 2.7 & 12.7 & 9.3 & 10.3 & 7.7 & 14.3 & 13.7 \\
\hline EG 830 & 206.3 & 194.3 & 9.3 & 9.7 & - & 4.0 & 14.7 & 10.0 & 12.7 & 8.0 & 13.7 & 12.0 \\
\hline EG 481 & 205.0 & 195.3 & 9.3 & 9.7 & - & 4.0 & 14.0 & 11.0 & 8.7 & 6.3 & 9.7 & 9.7 \\
\hline B35-1 & 196.3 & 174.0 & 11.0 & 11.3 & - & 3.3 & 15.0 & 11.7 & 14.0 & 7.3 & 30.3 & 25.0 \\
\hline B-35 & 182.3 & 174.3 & 13.0 & 13.0 & - & 4.0 & 11.3 & 5.7 & 13.3 & 6.3 & 25.7 & 22.7 \\
\hline EG 870 & 244.7 & 237.0 & 10.7 & 11.3 & - & 2.7 & 6.3 & 5.3 & 10.0 & 7.0 & 22.7 & 22.3 \\
\hline EG 473 & 127.7 & 114.7 & 8.3 & 8.3 & - & 3.3 & 15.7 & 12.0 & 9.3 & 6.7 & 10.3 & 11.0 \\
\hline EG 843 & 206.0 & 199.3 & 12.7 & 11.0 & - & 2.3 & 11.3 & 5.7 & 10.7 & 6.7 & 27.0 & 30.0 \\
\hline Mean & 249.5 & 222.1 & 10.7 & 10.5 & - & 3.3 & 12.3 & 8.1 & 10.3 & 6.8 & 18.7 & 17.9 \\
\hline $\mathbf{L S D}_{0.05}$ & 41.6 & 57.2 & 1.0 & 1.2 & - & 1.4 & 5.1 & 4.9 & 4.7 & 2.5 & 3.8 & 3.5 \\
\hline CV (\%) & 8.8 & 13.4 & 4.5 & 6.2 & - & 17.5 & 15.0 & 15.8 & 24.8 & 19.1 & 8.8 & 9.1 \\
\hline Fprob & $* * *$ & $* * *$ & $* * *$ & $* * *$ & - & * & $* * *$ & * & NS & * & $* * *$ & $* * *$ \\
\hline
\end{tabular}

LA = Leaf area $\left(\mathrm{cm}^{2}\right)$, NoL $=$ Number of leaves, StG $=$ Stay-green score, PEX = Peduncle exsertion $(\mathrm{cm})$, PaW $=$ Panicle width $(\mathrm{cm})$ and PaL, Panicle length $(\mathrm{cm}), \mathrm{LSD}=$ Least significant differences, $\mathrm{CV}(\%)=$ Coefficient of variance and Fprob. $=$ F probability differences at ${ }^{* *} \mathrm{P} \leq 0.01,{ }^{* *} \mathrm{P} \leq 0.01$, ${ }^{* * *} \mathrm{P} \leq 0.001$.

ments. A wide range of variation was recorded in plant height, which ranged from 92 to $227.7 \mathrm{~cm}$ under drought stress, while under the control conditions it ranged from 97.3 to $266.7 \mathrm{~cm}$. The overall mean plant height of the accessions was lower under drought stress $(175.3 \mathrm{~cm})$ than under the irrigated treatment $(191.8 \mathrm{~cm})$. Days to $50 \%$ 
flowering under drought stress ranged from 54 to 80 days after sowing, whereas the range under control conditions was 50 to 74 days after sowing. Under stress condition, EG 473, EG 711, EG 481, EG 830 and EG 813 were among the early flowering genotypes that took 54, 57, 58 and 59 days to flower respectively while EG 843 (80) was the latest genotype to flower. Days to maturity under stress ranged from 95 to 115 days after sowing, where as the range under the control conditions was 93 to 107 (Table 4). Under the drought stress conditions,

Table 4. Mean genotype values for plant phenology and yield related component traits under drought stress (Str) and control (Con) conditions, Hamelmalo Agricultural College.

\begin{tabular}{|c|c|c|c|c|c|c|c|c|c|c|c|c|}
\hline \multirow{2}{*}{ Genotype } & \multicolumn{2}{|c|}{ PLHT } & \multicolumn{2}{|c|}{ DFL } & \multicolumn{2}{|c|}{ DM } & \multicolumn{2}{|c|}{ OAS } & \multicolumn{2}{|c|}{ GY } & \multicolumn{2}{|c|}{$\mathrm{BM}$} \\
\hline & Con & Str & Con & Str & Con & Str & Con & Str & Con & Str & Con & Str \\
\hline EG 469 & 223.7 & 202.3 & 62.7 & 70.7 & 94.7 & 100.3 & 3.5 & 3.5 & 2.9 & 2.7 & 19.9 & 16.7 \\
\hline EG 849 & 184.7 & 169.7 & 59.3 & 62.3 & 94.7 & 97.0 & 3.3 & 3.5 & 3.3 & 2.4 & 14.8 & 11.0 \\
\hline EG 537 & 266.7 & 227.7 & 66.0 & 71.0 & 102.3 & 106.7 & 1.7 & 1.0 & 2.2 & 2.2 & 25.4 & 17.8 \\
\hline Hamelmaloo & 133.7 & 129.7 & 63.3 & 68.3 & 97.0 & 100.7 & 4.0 & 3.5 & 2.5 & 2.6 & 22.4 & 18.1 \\
\hline EG 806 & 198.3 & 176.7 & 54.7 & 61.3 & 94.7 & 99.7 & 3.8 & 3.5 & 2.4 & 2.3 & 14.2 & 7.9 \\
\hline EG 782 & 189.7 & 175.0 & 60.3 & 68.7 & 95.7 & 104.0 & 3.8 & 3.5 & 2.1 & 1.8 & 16.4 & 15.6 \\
\hline EG 797 & 135.7 & 124.7 & 61.3 & 67.0 & 96.0 & 104.7 & 3.5 & 3.5 & 2.2 & 1.6 & 11.1 & 10.4 \\
\hline EG 791 & 192.7 & 177.7 & 62.3 & 71.3 & 96.3 & 104.7 & 3.7 & 4.0 & 2.1 & 2.3 & 13.5 & 12.5 \\
\hline EG 815 & 187.7 & 161.3 & 62.0 & 70.3 & 103.0 & 110.7 & 1.2 & 1.5 & 1.9 & 0.8 & 18.1 & 8.9 \\
\hline EG 836 & 210.0 & 202.7 & 61.3 & 67.0 & 95.3 & 99.0 & 3.2 & 3.7 & 3.2 & 2.7 & 21.1 & 17.3 \\
\hline EG 883 & 236.7 & 218.3 & 64.7 & 68.3 & 96.3 & 99.7 & 3.3 & 3.0 & 3.1 & 2.6 & 20.6 & 17.0 \\
\hline EG 885 & 202.3 & 181.7 & 63.0 & 66.7 & 95.3 & 107.7 & 3.3 & 3.0 & 3.0 & 2.9 & 17.0 & 14.4 \\
\hline EG 889 & 244.0 & 220.3 & 62.0 & 68.0 & 103.0 & 111.3 & 2.8 & 1.8 & 1.9 & 1.5 & 20.4 & 12.6 \\
\hline EG 1224 & 171.0 & 126.0 & 63.3 & 68.0 & 102.3 & 110.3 & 2.3 & 1.3 & 1.5 & 1.0 & 14.8 & 9.6 \\
\hline EG 526 & 193.3 & 170.3 & 61.0 & 67.7 & 101.0 & 108.0 & 2.3 & 2.5 & 2.3 & 2.2 & 19.4 & 13.7 \\
\hline EG 711 & 189.3 & 188.3 & 52.0 & 57.0 & 93.3 & 96.3 & 3.5 & 3.7 & 2.9 & 2.6 & 11.6 & 8.0 \\
\hline EG 783 & 197.3 & 187.0 & 60.7 & 65.3 & 95.7 & 100.0 & 2.8 & 3.7 & 3.0 & 2.6 & 19.9 & 14.7 \\
\hline EG 813 & 197.7 & 178.0 & 53.7 & 58.7 & 93.3 & 94.7 & 4.0 & 3.3 & 2.6 & 2.0 & 10.4 & 6.4 \\
\hline EG 830 & 189.3 & 177.3 & 52.0 & 59.3 & 94.7 & 99.7 & 3.0 & 3.5 & 2.4 & 2.2 & 9.9 & 7.0 \\
\hline EG 481 & 159.3 & 156.3 & 50.3 & 58.0 & 94.7 & 97.3 & 3.8 & 3.0 & 3.1 & 2.7 & 12.2 & 8.7 \\
\hline B35-1 & 203.3 & 188.7 & 69.0 & 71.0 & 104.0 & 113.7 & 4.0 & 3.0 & 2.5 & 2.1 & 24.6 & 20.0 \\
\hline B-35 & 97.3 & 92.0 & 69.7 & 75.3 & 106.7 & 114.3 & 3.7 & 3.2 & 1.4 & 1.6 & 17.8 & 14.1 \\
\hline EG 870 & 198.0 & 183.3 & 61.7 & 69.7 & 101.0 & 107.3 & 2.0 & 2.3 & 1.9 & 1.6 & 17.9 & 10.4 \\
\hline EG 473 & 159.7 & 153.7 & 50.0 & 53.7 & 94.7 & 96.0 & 3.8 & 3.0 & 2.3 & 2.0 & 7.1 & 5.3 \\
\hline EG 843 & 234.3 & 212.7 & 74.0 & 79.7 & 103.0 & 114.7 & 1.3 & 1.5 & 1.4 & 1.8 & 15.0 & 13.3 \\
\hline Mean & 191.8 & 175.3 & 60.8 & 67.0 & 97.9 & 104 & 3.1 & 2.9 & 2.4 & 2.1 & 16.6 & 12.5 \\
\hline LSD $_{0.05}$ & 19.3 & 20.9 & 4.4 & 4.3 & 3.1 & 6.9 & 0.6 & 0.8 & 0.8 & 0.9 & 5.1 & 5.7 \\
\hline CV (\%) & 4.2 & 2.6 & 3.1 & 3.6 & 1.7 & 3.4 & 8.1 & 15.8 & 18.0 & 21.4 & 2.0 & 24.7 \\
\hline Fprob & $* * *$ & $* * *$ & $* * *$ & $* * *$ & $* * *$ & $* * *$ & $* * *$ & $* * *$ & ** & $* * *$ & $* * *$ & $* * *$ \\
\hline
\end{tabular}

where, PLHT = Plant height, DFL = Days to 50\% flowering, DM = Days to physiological maturity, OAS, Over all agronomic score, GY = Grain yield $\left(\mathrm{t} \cdot \mathrm{ha}^{-1}\right), \mathrm{BM}=$ Total biomass $\left(\mathrm{t} \cdot \mathrm{ha}^{-1}\right), \mathrm{HI}(\%)=$ Harvest index, LSD = Least significant differences, CV $(\%)=$ Coefficient of variance and Fprob. $=$ F probability differences at ${ }^{* *} \mathrm{P} \leq 0.01,{ }^{* * *} \mathrm{P} \leq 0.001$. 
delays in flowering and maturity were also observed in most of the accessions when compared with the fully irrigated; values ranged from 3 to 9 days (DFL) and 1 to 12 days (DM). This indicated that drought stress affected flowering and maturity dates whereby the two parameters were delayed. Delay in flowering and maturity is a strong indication of sensitivity and is caused by growth retardation during soil drying in response to stress as reported by [26]. Similar effects of delayed flowering and maturity due to drought stress has been reported in rice during the reproductive stage [27].

The grain yield (GY) of accessions varied significantly under drought stress, ranging from 0.8 to $2.9 \mathrm{t}^{\mathrm{h}} \mathrm{ha}^{-1}$ with an average of 2.1, similarly under the control condition the yield level of the genotypes varied from 1.4 to $3.3 \mathrm{t} \cdot \mathrm{ha}^{-1}$. Among the highest yielding genotypes under drought stress and control condition includes EG 885, EG 469, EG 481, EG 849, Hamelmalo, EG 836 and EG 711 (Table 4). Reduction in grain yield, leaf area, plant height, panicle width and exsertion were recorded on the genotypes due to drought stress as compared to the full irrigation. The decrease in yield, leaf area, plant height and panicle related traits showed high sensitivity of genotypes to drought stress. Similar yield decreases were also reported in wheat and rice [28] and decrease in leaf area [29]. The results of the current study indicate a strong association between drought stress at developmental stage and performance.

Combined mean analysis of main plot irrigation levels were significant for all the traits studied except for harvest index, biomass, panicle length, overall agronomic score, seedling vigor and number of leaves (Table 5). The high significant level of the mean squares traits indicated that the existence of high degree of variability among... the genotypes that could be exploited for sorghum improvement.

\subsection{Correlation Analysis among Morpho-Physiological Parameters under Drought Stress}

Overall agronomic score was positively associated with stay green, grain yield and harvest index and negatively associated with days to 50\% flowering and physiological maturity and panicle length. Grain yield was strongly correlated with stay-green and overall agronomic scores but negatively associated with days to maturity and panicle length. The study is in agreement with the findings of other authors proving that drought tolerant genotypes produce higher yields than drought-susceptible genotype under drought stressed environments [30]. Correlations analysis revealed that the genotypes with early flowering produced more grain yield and scored higher harvest index (significantly negative correlation). The total biomass showed positive association with days to flowering, number of leaves and leaf area but was negatively associated with harvest index (Table 6). Plant height exhibited significant positive correlation with days to flowering and negative correlation with harvest index. Similar relationships were recorded in other studies on sorghum [31]-[33].

Table 5. Mean squares of combined analysis of variance of data from14 traits recorded on 25 sorghum landraces at Hamelmalo Agricultural College in 2014.

\begin{tabular}{|c|c|c|c|c|c|}
\hline \multirow[b]{2}{*}{ Traits } & \multicolumn{5}{|c|}{ Mean Square } \\
\hline & $\begin{array}{l}\text { Replication } \\
(\mathrm{DF}=2)\end{array}$ & $\begin{array}{c}\text { Irrigation } \\
\text { Level (DF = 1) }\end{array}$ & $\begin{array}{l}\text { Genotypes } \\
(\mathrm{DF}=24)\end{array}$ & $\begin{array}{c}\text { Irrigation } \times \text { Genotype } \\
(D F=24)\end{array}$ & $\begin{array}{c}\text { Error } \\
(\mathrm{DF}=96)\end{array}$ \\
\hline Days to $50 \%$ flowering & 4.90 & $12.44^{* *}$ & $210.20^{* * *}$ & 5.06 & 7.05 \\
\hline Days to maturity & 7.2 & $1344.01^{* *}$ & $150.28^{* * *}$ & 13.9 & 10.69 \\
\hline Grain yield & 59.53 & $322.15^{*}$ & $170.18^{* * *}$ & 19.29 & 31.50 \\
\hline Harvest index & 156.01 & 253.11 & $395.93^{* * *}$ & 18.55 & 38.80 \\
\hline Leaf area & 950.40 & $28098.7^{* * *}$ & $19232.3^{* * *}$ & 1422.60 & 929.40 \\
\hline Number of leaves & 0.14 & 1.92 & $6.77^{* * *}$ & 0.70 & 0.49 \\
\hline Plant height & 1682.2 & $10300.3^{*}$ & $6980.5^{* * *}$ & 163.6 & 149.50 \\
\hline Panicle length & 12.05 & 24.81 & $258.29^{* * *}$ & $11.23^{* *}$ & 5.05 \\
\hline Panicle width & 0.04 & $454.14^{* *}$ & $11.83^{* *}$ & 3.38 & 5.27 \\
\hline Peduncle exsertion & 129.38 & $678.41^{* * *}$ & $40.28^{* * *}$ & 5.33 & 9.28 \\
\hline Overall agronomic score & 0.28 & 1.40 & $3.90^{* * *}$ & $0.43^{*}$ & 0.20 \\
\hline Seedling vigor & 2.97 & 8.40 & $1.49^{* * *}$ & 0.20 & 0.35 \\
\hline Biomass & 19.84 & 131.97 & $22.17^{* * *}$ & 1.54 & 2.18 \\
\hline Stay green & 1.9 & - & $2.03^{* *}$ & - & 0.76 \\
\hline
\end{tabular}


Table 6. Simple correlation analysis among morpho-physiological traits recorded under drought stress conditions.

\begin{tabular}{|c|c|c|c|c|c|c|c|c|c|c|c|c|}
\hline & $\mathrm{BM}$ & DFL & DM & GY & HI & LA & NoL & OAS & PEX & PLH & $\mathrm{PaL}$ & StG \\
\hline $\mathrm{BM}$ & 1.00 & & & & & & & & & & & \\
\hline DFL & $0.65^{* * * *}$ & 1.00 & & & & & & & & & & \\
\hline DM & 0.36 & $0.81^{* * *}$ & 1.00 & & & & & & & & & \\
\hline GY & 0.31 & $-0.30^{*}$ & $-0.58^{* * *}$ & 1.00 & & & & & & & & \\
\hline HI & $-0.54^{* *}$ & $-0.66^{* * *}$ & $-0.47^{*}$ & 0.28 & 1.00 & & & & & & & \\
\hline LA & $0.46^{*}$ & 0.37 & -0.04 & 0.17 & $-0.52^{* * *}$ & 1.00 & & & & & & \\
\hline NoL & $0.56^{* *}$ & $0.53^{* *}$ & 0.33 & 0.11 & $-0.41^{*}$ & $0.41^{*}$ & 1.00 & & & & & \\
\hline OAS & -0.01 & $-0.40^{* *}$ & $-0.61^{* *}$ & $0.60^{* *}$ & 0.21 & 0.03 & -0.09 & 1.00 & & & & \\
\hline PEX & -0.28 & $-0.58^{* *}$ & -0.34 & 0.28 & $0.58^{* *}$ & $-0.55^{* *}$ & $-0.48^{*}$ & 0.23 & 1.00 & & & \\
\hline PLH & 0.29 & $0.40^{*}$ & -0.07 & 0.33 & 0.04 & 0.21 & -0.04 & -0.19 & 0.24 & 1.00 & & \\
\hline $\mathrm{PaL}$ & $0.40^{*}$ & $0.75^{* * *}$ & $0.69^{* *}$ & $-0.40^{*}$ & $-0.46^{*}$ & 0.25 & 0.30 & $-0.53^{*}$ & -0.32 & 0.23 & 1.00 & \\
\hline StG & 0.24 & -0.28 & $-0.51^{* *}$ & $0.78^{* * * *}$ & 0.26 & 0.29 & -0.02 & $0.48^{*}$ & 0.22 & 0.32 & -0.37 & 1.00 \\
\hline
\end{tabular}

\subsection{Assessment of Heritability, Phenotypic and Genotypic Coefficients of Variations}

The results on the component of variance and heritability revealed that all the traits had considerable values of phenotypic and genotypic coefficients of variation (PCV and GCV respectively) among the sorghum accessions (Table 5). High PCV and GCV were recorded for majority of the characters studied except for days to flowering, days to maturity and number of leaves. However, PLHT gave rise to the highest coefficients of variation (both PCV and GCV) followed by HI, PaL and SV. On the other hand parameters such as GY, BM, PaW, PEXS, OAS and StG showed moderate phenotypic and genotypic coefficient of variation (Table 7). The current results on variance component showed that the phenotypic variances $\left(\sigma^{2} \mathrm{p}\right)$ and PCVs were slightly higher than the genotypic variance $\left(\sigma^{2} \mathrm{~g}\right)$ and GCV for all the characters, suggesting the least influence of environment in the expression of these characters. Generally the results depicted that high to moderate values of PCV and GCV for all the traits except for days to flowering (DFL), days to maturity (DM) and number of leaves (NoL). These results proved that selection could be effective for these traits but also indicated that the genotypes have a broad base genetic background and existence of substantial variability among the accessions, ensuring ample scope for their improvement through selection. These observations are in agreement with other researchers findings [34] [35] in maize. In addition, the characters showed higher phenotypic and genotypic variance estimates than the error variance estimates indicating that expressions for most of the characters were genetic, which can be exploited in breeding programs. This finding is in agreement with other authors on several quantitative characters studies in sorghum genotypes [36] [37].

Heritability in broad-sense was medium to high for most of the morpho-physiological traits among the sorghum accessions in this study. The highest heritability was recorded for days to flowering, days to maturity, number of leaves, panicle length and overall agronomic score traits while it was moderate for seedling vigour, grain yield, biomass, harvest index, plant height, peduncle exsertions and productive tillers. The lowest heritability was scored for panicle width and stay-green score (Table 7).

High heritability estimates recorded in some characters such as panicle length, number of leaves per plant, days to $50 \%$ flowering and days to physiological maturity is in agreement with the finding of sorghum genetic variability studies [38] and indicated that these characters could respond to selection pressure. Stay-green and grain yield showed low heritability and implied selection for such trait reduce the effectiveness of phenotypic selection. Selection for such low heritability quantitative traits such as yield and stay-green is a common problem encountered in conventional breeding programs. This low heritability could be partially overcome through the use of markers linked to QTLs for the target traits that enables individuals to be scored based on their genetic 
Table 7. Estimates of means, \% of reduction, genotypic and phenotypic variation, genotypic and phenotypic coefficients of variation and heritability for yield and yield components under drought stress and control conditions.

\begin{tabular}{|c|c|c|c|c|c|c|c|c|}
\hline \multirow[t]{2}{*}{ Traits } & \multicolumn{2}{|c|}{ Mean } & \multirow{2}{*}{$\%$ of reduction } & \multirow{2}{*}{$\delta^{2} \mathbf{p}$} & \multirow{2}{*}{$\delta^{2} \mathbf{g}$} & \multirow{2}{*}{ PCV (\%) } & \multirow{2}{*}{ GCV (\%) } & \multirow{2}{*}{$\mathbf{h}^{2}{ }_{\mathrm{BS}}(\%)$} \\
\hline & Control & Stress & & & & & & \\
\hline Seedling vigor & 1.5 & 2.0 & -33.3 & 0.7 & 0.4 & 46.5 & 35.1 & 57.1 \\
\hline Days to flowering & 60.8 & 67.0 & -10.2 & 74.8 & 67.7 & 13.5 & 12.9 & 90.6 \\
\hline Days to maturity & 97.9 & 104.0 & -6.2 & 57.2 & 46.5 & 7.5 & 6.8 & 81.3 \\
\hline Grain yield & 2.4 & 2.1 & 12.5 & 77.7 & 46.2 & 39.0 & 30.1 & 59.5 \\
\hline Biomass & 16.6 & 12.5 & 24.7 & 8.9 & 6.7 & 45.8 & 39.7 & 75.2 \\
\hline Harvest index & 16.8 & 19.5 & -16.1 & 157.8 & 119.0 & 66.8 & 58.0 & 75.4 \\
\hline Plant height & 191.8 & 175.3 & 8.6 & 65409.0 & 51061.6 & 139.3 & 123.1 & 78.1 \\
\hline No. of leaves & 10.7 & 10.5 & 1.9 & 2.6 & 2.1 & 15.2 & 13.6 & 80.7 \\
\hline Panicle length & 18.7 & 17.9 & 4.3 & 89.5 & 84.4 & 50.6 & 49.1 & 94.3 \\
\hline Panicle width & 10.3 & 6.8 & 34.0 & 7.5 & 2.2 & 31.8 & 17.1 & 29.0 \\
\hline Peduncle exsertion & 12.0 & 8.0 & 33.3 & 19.6 & 10.3 & 43.4 & 31.5 & 52.6 \\
\hline Agronomic score & 3.1 & 2.9 & 6.5 & 1.4 & 1.2 & 39.9 & 37.0 & 86.0 \\
\hline Productive tiller & 1.7 & 1.6 & 5.9 & 0.4 & 0.3 & 39.3 & 34.6 & 77.6 \\
\hline Stay-green & - & 3.5 & - & 1.1 & 0.3 & 30.4 & 15.2 & 25.0 \\
\hline
\end{tabular}

where, $\delta^{2} \mathrm{p}=$ phenotypic variation, $\delta^{2} \mathrm{~g}=$ genotypic variation, GCV $(\%)$ = genotypic coefficient variance, PCV (\%) = phenotypic coefficient variance and $\mathrm{h}_{\mathrm{BS}}^{2}(\%)=$ heritability in broad-sense.

makeup rather than their phenotypic features. Genetic studies of stay-green have generally indicated a complex pattern of inheritance, both dominant and recessive expression have been reported [7].

\subsection{Principal Component Analysis of Various Morpho-Physiological Traits in Sorghum}

Principal component (PC) analysis showed that out of the seven the first 4 explained majority of the total variation. These four PCs with Eigen value $>1$ contributed $74.6 \%$ of the total variability amongst the sorghum genotypes assessed for various morpho-physiological traits (Table 8). However, the remaining 3 components contributed only $15.4 \%$ towards the total morpho-physiological diversity for this set of sorghum genotypes. The PC I contributed maximum towards the variability (32.8\%) followed by PC II (22.8\%), PC III (10.98\%) and PC IV (8.0\%). The most important characters in PC I was due to variations among the accessions mainly for days to $50 \%$ flowering, days to maturity, harvest index, peduncle exsertion and panicle length. Besides, days to flowering, days to maturity and panicle length had considerable positive factor loadings on PC I. Similarly the PC II was related to diversity among sorghum genotypes due to specific biomass, grain yield, seedling vigor, stay-green and leaf area. The PC III was explained mainly by variation among genotypes resulted from plant height, peduncle exsertion, overall agronomic score and panicle length. In this principal component plant height, peduncle exsertion and panicle length have positive factor while overall agronomic scores contributed negatively. The fourth (PC IV) was explained negatively by the variations resulting from leaf area, plant height, number of productive tillers, panicle width and seedling vigor (Table 8).

Considering a minimum threshold Eigen value of one, the four principal components (PCs) accounted for a cumulative of about $74 \%$ of the whole phenotypic diversity observed among the germplasm accessions. These results were in similar to those of different authors who worked on different agro-morphological traits in sorghum [39] [40]. Moreover, the principal components analysis also showed that the variation in the germplasm accessions cannot be explained on the basis of few characters.

This, in turn, implied that a number of traits were involved in explaining the gross variance among the accessions. In order of diminishing importance, the explanation of greater proportion of the entire phenotypic diver- 
Table 8. Principle component analysis of various morpho-physiological traits recorded in sorghum under drought stress conditions.

\begin{tabular}{|c|c|c|c|c|c|c|c|}
\hline & PC I & PC II & PC III & PC IV & PC V & PC VI & PC VII \\
\hline Eigen value & 4.9 & 3.2 & 1.6 & 1.2 & 0.9 & 0.8 & 0.6 \\
\hline$\%$ total variance & 32.8 & 22.9 & 10.9 & 8.0 & 6.5 & 5.0 & 3.9 \\
\hline Cumulative variance $\%$ & 32.8 & 55.7 & 66.6 & 74.6 & 81.1 & 86.1 & 90 \\
\hline \multicolumn{8}{|c|}{ Factor loading by various traits } \\
\hline Biomass & 0.22 & 0.39 & 0.02 & 0.13 & 0.19 & 0.09 & 0.21 \\
\hline Days to $50 \%$ flowering & 0.40 & 0.13 & 0.06 & 0.03 & 0.22 & 0.17 & 0.06 \\
\hline Days to maturity & 0.38 & -0.10 & 0.17 & 0.21 & 0.29 & 0.14 & 0.02 \\
\hline Grain yield & -0.25 & 0.40 & -0.04 & 0.09 & 0.06 & -0.07 & -0.03 \\
\hline Harvest index & -0.34 & -0.12 & 0.19 & 0.24 & 0.09 & -0.22 & -0.45 \\
\hline Leaf area & 0.16 & 0.31 & -0.29 & -0.43 & -0.09 & -0.33 & 0.03 \\
\hline Number of leaves & 0.24 & 0.27 & -0.17 & 0.19 & -0.14 & 0.26 & -0.67 \\
\hline Overall agronomic score & -0.27 & 0.19 & -0.35 & 0.14 & -0.02 & 0.33 & 0.41 \\
\hline Peduncle exsertion & -0.30 & -0.039 & 0.45 & 0.17 & -0.02 & 0.15 & 0.17 \\
\hline Plant height & -0.02 & 0.26 & 0.52 & -0.39 & 0.18 & -0.21 & -0.07 \\
\hline Number of productive tiller & -0.14 & -0.16 & -0.12 & -0.39 & 0.70 & 0.36 & -0.14 \\
\hline Panicle length & 0.36 & 0.05 & 0.32 & 0.03 & -0.10 & -0.13 & 0.24 \\
\hline Panicle width & -0.10 & 0.22 & 0.29 & -0.39 & -0.42 & 0.58 & -0.10 \\
\hline Seedling vigor & 0.09 & -0.39 & -0.14 & -0.40 & -0.18 & -0.04 & 0.04 \\
\hline Stay-green & -0.24 & 0.37 & -0.06 & -0.07 & 0.19 & -0.24 & 0.01 \\
\hline
\end{tabular}

sity involved were panicle traits (i.e. its panicle width and peduncle exsertion), leaf traits (it's stay-green and leaf area), yield related traits (grain weight and biomass) and plant phenology (plant height, days to flowering and maturity). This further confirmed the previous results that also described the importance of these traits in contributing towards the overall diversity of the sorghum germplasm landraces [41].

\subsection{Morphological Cluster Analysis}

The percentage of similarity between accessions was $90 \%$ (Figure 1). The resulting phenetic dendrogram revealed three main clusters (I, II and III) at a genetic distance of 0.9.

Cluster I contained seven accessions and further classified into two sub clusters, EG 469, EG 883 and EG 849 in one subgroup and EG 537, EG 843, EG 889 and B-35-1 in the second at a genetic similarity of 0.92 . All accessions in cluster I were from Gash Barka and South region and were characterized by flat seed, small to medium grain size with red and brown grain color and tall in their height. Furthermore, accessions in this cluster are known to have semi-compact elliptic panicle and non-lustrous as well as elliptical grain shape. Accessions EG 469, EG 883 and EG 889 were known as Bazenay family in Gash Barka region.

Cluster II contained the 15 accessions (Figure 1) out of which eight were from Gash Barka, five from Anseba and two from the Southern region with varied morphological characters. All accessions in this cluster were characterized by early flowering, medium plant height, round grain shape, red grain color, and compact to semicompact bent type panicles. Two accessions, EG 830 and EG 711 clustered very closely from the remaining accessions in cluster II and were the most similar accessions at a genetic similarity coefficient of 0.99 .

Cluster III contained three genotypes namely, B-35, Hamelmalo and EG 797. Genotype B-35 was from ICRISAT, Hamelmalo is recently released variety in Anseba region and EG 797 is an accession from Gash Barka. 


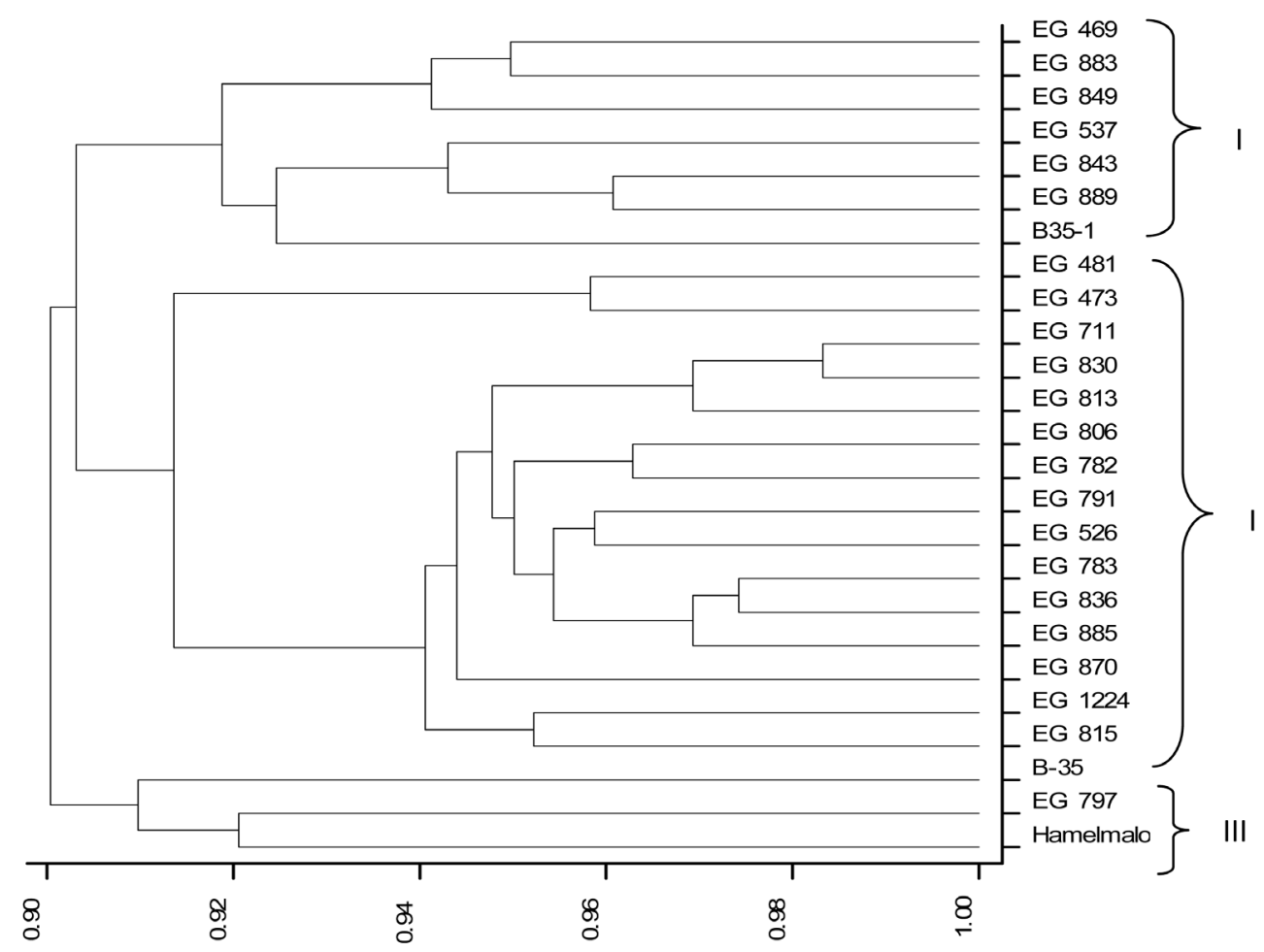

Figure 1. Phenetic dendrogram generated using morphological data of 25 sorghum accessions depicting their relationships based on UPGMA clustering comparisons

These genotypes were characterized by short plant height, red glume color, round grain shape, chalky white and brown grain color. Genotype B-35 was separated from the other two genotypes within sub cluster III.

The accessions were clustered together based mainly on geographical sites and pedigree relationship. Similar clustering was reported on sorghum accessions studied based on their collection site and pedigree relationship [42]-[44]. Likewise, studies on sorghum accessions from eastern and central Ethiopia showed the existence of high level morphological variations implying that there is need for genetic resources collection and maintenance [45] [46].

Overall, the cluster analysis confirmed the presence of variation among genotypes. Besides, the accessions in cluster I was also known for their drought tolerance and high yielding.

\section{Conclusion}

The current study identified seven promising genotypes (EG 885, EG 469, EG 481, EG 849, Hamelmalo, EG 836 and EG 711) for post-flowering drought tolerance that could be used by breeders in sorghum improvement programs. Grain yield under drought stress was influenced by many reproductive growth processes such as leaf area, panicle exsertion, panicle length and width, as well as days to flowering and maturity. The morphological dendrogram demonstrated variation of accessions based on morphological traits and collection region, and pedigree could be a valuable source for the sorghum improvement programs in the three geographical regions, Gash Barka, Anseba and South in particular and Eritrea in general.

\section{Acknowledgements}

We deeply indebted for the financial support from the ADB program and the National Commission for Higher Education of Eritrea for this field experiment. We also thank the senior scientists of Jomo Kenyatta University of Agriculture and Technology and Hamelmalo Agricultural College for back stopping and valuable comments. We acknowledge the National Genbank, NARI of Eritrea and ICRISAT East Africa for providing the seed samples used in this study. 


\section{References}

[1] Food and Agriculture Organization Crop Production Statistics (FAOSTAT) (2014) World Sorghum Production and Utilization. FAO, Rome.

[2] Hall, A.E. (1993) Is Dehydration Tolerance Relevant to Genotypic Differences in Leaf Senescence and Crop Adaptation to Dry Environments. In: Close, T.J. and Bray, E.A., Eds., Plant Responses to Cellular Dehydration during Environmental Stress, 1-10.

[3] Blum A., Mayer, J. and Golan, G. (1988) Agronomic and Physiological Assessments of Genotypic Variation for Drought Resistance in Sorghum. Australian Journal of Agricultural Research, 40, 49-61. http://dx.doi.org/10.1071/AR9890049

[4] Ramirez, P. and Kelly, J.D. (1998) Traits Related to Drought Resistance in Common Bean. Euphytica, 99, 127-136. http://dx.doi.org/10.1023/A:1018353200015

[5] Kebede, H., Subudhi, P.K., Rosenow, D.T. and Nguyen, H.T. (2001) Quantitative Trait Loci Influencing Drought Tolerance in Grain Sorghum (Sorghum bicolor L. Moench). Theoretical and Applied Genetics, 103, 266-276. http://dx.doi.org/10.1007/s001220100541

[6] Ejeta, G. and Knoll, J.E. (2007) Marker-Assisted Selection in Sorghum. In: Varshney, R.K. and Tuberosa, R., Eds., Genomic-Assisted Crop Improvement: Vol. 2: Genomics Applications in Crops, Springer Publications, The Netherlands, 187-205. http://dx.doi.org/10.1007/978-1-4020-6297-1_9

[7] Tuinstra, M.R., Grote, E.M., Goldsbrough, P.B. and Ejeta, G. (1997) Genetic Analysis of Post-Flowering Drought Tolerance and Components of Grain Development in Sorghum bicolor (L.) Moench. Molecular Breeding, 3, 439-448. http://dx.doi.org/10.1023/A:1009673126345

[8] Blum, A. (1979) Genetic Improvement of Drought Resistance in Crop Plants. A Case for Sorghum. In: Mussel, H. and Staples, R.C., Eds., Stress Physiology in Crop Plants, John Wiley and Sons, Inc., New York, 429-245.

[9] Rosenow, D.T. and Clark, L.E. (1995) Drought and Lodging Resistance for Quality Sorghum Crop. Proceedings of the 50th Annual Corn and Sorghum Industry Research Conference, Chicago, 6-7 December 1995, 82-97.

[10] Rosenow, D.T., Ejeta, G., Clark, L.E., Gilbert, M.L., Henzell, R.G., Borrell, A.K. and Muchow, R.C. (1996) Breeding for Pre- and Post-flowering Drought Stress Resistance in Sorghum. In: Rosenow, D.T. and Yohe, J.M., Eds., Proceedings of the International Conference on Genetic Improvement of Sorghum and Pearl Millet, Lubbock, 22-27 September 1996, 400-411.

[11] Rosenow, D.T. (1977) Breeding for Lodging Resistance in Sorghum. In: Loden, H.D. and Wilkinson, D., Eds., Proceedings of the 32nd Annual Corn and Sorghum Industry Research Conference, American Seed Trade Association, Washington DC, 171-185

[12] Xu, W.W., Subudhi, P.K., Crasta, O.R., Rosenow, D.T., Mullet, J.E. and Nguyen, H.T. (2000) Molecular Mapping of QTLs Conferring Staygreen in Grain Sorghum (Sorghum bicolor L. Moench). Genome, 43, 461-469. http://dx.doi.org/10.1139/gen-43-3-461

[13] Borrell, A.K., Hammer, G.L. and Douglas, A.C.L. (2000) Does Maintaining Green Leaf Area in Sorghum Improve Yield under Drought? I. Leaf Growth and Senescence. Crop Science, 40, 1026-1037. http://dx.doi.org/10.2135/cropsci2000.4041026x

[14] Ahmad, S.Q., Khan, S., Ghaffar, M. and Ahmad, F. (2011) Genetic Diversity Analysis for Yield and Other Parameters in Maize (Zea mays L.) Genotypes. Asian Journal of Agricultural Sciences, 3, 385-388.

[15] Mitra, J. (2001) Genetics and Genetic Improvement of Drought Tolerance in Crop Plants. Current Science, 80, 758762.

[16] Waqar-Ul-Haq, M., Malik, F., Rashid, M., Munir, M. and Akram, Z. (2008) Evaluation and Estimation of Heritability and Genetic Advancement for Yield Related Attributes in Wheat Lines. Pakistan Journal of Botany, 40, 1699-1702.

[17] Laghari, K.A., Sial, M.A., Afzal Arain, M.A., Mirbahar, A.A., Pirzada, A.J., Dahot, M.U. and Mangrio, S.M. (2010) Heritability Studies of Yield and Yield Associated Traits in Bread Wheat. Pakistan Journal of Botany, 42, 111-115.

[18] Wanous, M.K., Miller, F.R. and Rosenow, D.T. (1991) Evaluation of Visual Rating Scales for Green Leaf Retention in Sorghum. Crop Science, 31, 1691-1694. http://dx.doi.org/10.2135/cropsci1991.0011183X003100060063x

[19] Reddy, B.V.S., Ramaiah, B., Kumar, A.A. and Reddy, P.S. (2007) Evaluation of Sorghum Genotypes for the StayGreen Trait and Grain Yield. SAT E Journal, 3, 1-4.

[20] Payne, R.W., Murray, D.A., Harding, S.A., Baird, D.B. and Soutar, D.M. (2011) An Introduction to Gen Stat for Windows. 14th Edition, VSN International, Hemel Hempstead.

[21] Sokal, R.R. and Michener, C.D. (1958) A Statistical Methods for Evaluating Relationships. University of Kansas Science Bulletin, 38, 1409-1448. 
[22] Assefa, K., Ketema, S., Tefera, H., Nguyen, H.T., Blum, A., Ayele, M., Bai, G., Simane, B. and Kefyalew, T. (1999) Diversity among Germplasm Lines of the Ethiopian Cereal Tef (Eragrostis tef (Zucc.) Trotter). Euphytica, 106, 87-97. http://dx.doi.org/10.1023/A:1003582431039

[23] Tsuji, W., Ali, M.E.K, Inanaga, S. and Sugimoto, Y. (2003) Growth and Gas Exchange of Three Sorghum Cultivars under Drought Stress. Biologia Plantarum, 46, 583-587. http://dx.doi.org/10.1023/A:1024875814296

[24] Khaliq, I., Irshad, A. and Ahsan, M. (2008) Awns and Flag Leaf Contribution towards Grain Yield in Spring Wheat (Triticum aestivum L.). Cereal Research Communication, 36, 65-76. http://dx.doi.org/10.1556/CRC.36.2008.1.7

[25] Karamanos, A.J. and Papatheohari, A.Y. (1999) Assessment of Drought Resistance of Crop Genotypes by Means of the Water Potential Index. Crop Science, 39, 1792-1797. http://dx.doi.org/10.2135/cropsci1999.3961792x

[26] Blum, A., Mayer, J., Golan, G. and Sinmena, B. (1999) Drought Tolerance of a Doubled Haploid Line Population of Rice in the Field. In: Ito, O., O’Toole, J. and Hardy, B., Eds., Genetic Improvement of Rice for Water-Limited Environments, International Rice Research Institute, Los Banos, 319-329.

[27] Sellamuthu, R., Liu, G.F., Ranganathan, C.B. and Serraj, R. (2011) Genetic Analysis and Validation of Quantitative Trait Loci Associated with Reproductive-Growth Traits and Grain Yield under Drought Stress in a Double Haploid Line Population of Rice (Oryza sativa L.). Field Crops Research, 124, 46-58. http://dx.doi.org/10.1016/j.fcr.2011.06.002

[28] Sheoran, I.S. and Saini, H.S. (1996) Drought-Induced Male Sterility in Rice: Changes in Carbohydrate Levels and Enzyme Activities Associated with the Inhibition of Starch Accumulation in Pollen. Sexual Plant Reproduction, 9, 161169. http://dx.doi.org/10.1007/BF02221396

[29] Khaliq, I., Irshad, A. and Ahsan, M. (2008) Awns and Flag Leaf Contribution towards Grain Yield in Spring Wheat (Triticum aestivum L.). Cereal Research Communications, 36, 65-76. http://dx.doi.org/10.1556/CRC.36.2008.1.7

[30] Cooper, M., Van Eeuwijik, F.A., Chapman, S.C., Podllich, D.W. and Loffler, C. (2006) Genotype by Environment Interactions Underwater-Limited Conditions. In: Ribaut, J.M., Ed., Drought Adaptation in Cereals, Haworth Press, Goteborg, 51-95.

[31] Murray, S.C., Rooney, W.L., Mitchell, S.E., Sharma, A., Klein, P.E., Mullet, J.E. and Kresovich, S. (2008) Genetic Improvement of Sorghum as a Biofuel Feedstock: II. QTL for Stem and Leaf Structural Carbohydrates. Crop Science, 48, 2180-2193. http://dx.doi.org/10.2135/cropsci2008.01.0068

[32] Ritter, K.B., Jordan, D.R., Chapman, S.C., Godwin, I.D., Mace, E.S. and McIntyre, C.L. (2008) Identification of QTL for Sugar-Related Traits in a Sweet $\times$ Grain Sorghum (Sorghum bicolor L. Moench) Recombinant Inbred Population. Molecular Breeding, 22, 367-384. http://dx.doi.org/10.1007/s11032-008-9182-6

[33] Zhao, Y.L., Dolat, A., Steinberger, Y., Wang, X., Osman, A. and Xie, G.H. (2009) Biomass Yield and Changes in Chemical Composition of Sweet Sorghum Cultivars Grown for Biofuel. Field Crops Research, 111, 55-64. http://dx.doi.org/10.1016/j.fcr.2008.10.006

[34] Rafique, M., Hussain, A., Mahmood, T., Alvi, A.W. and Alvi, B. (2004) Heritability and Interrelationships among Grain Yield and Yield Components in Maize (Zea mays L). International Journal of Agricultural Biology, 6, 11131114.

[35] Rafiq, C.M., Rafique, M., Hussain, A. and Altaf, M. (2010) Studies on Heritability, Correlation and Path Analysis in Maize (Zea mays L.). Agricultural Research, 48, 35-38.

[36] Basu, A.K. (1981) Variability and Heritability Estimate from Inter-Season Sorghum Cross. Indian Journal of Agricultural Science, 41, 116-117.

[37] Abu-Gasim, E.H. and Kambal, A.E. (1985) Variability and Interrelationship among Characters in Indigenous Grain Sorghum of the Sudan. Crop Science, 11, 308-309.

[38] Bello, O.B., Abdulmaliq, S.Y., Afolabi, M.S. and Ige, S.A. (2010) Correlation and Path Coefficient Analysis of Yield and Agronomic Characters among Open Pollinated Maize Varieties and Their F1 Hybrids in a Diallel Cross. African Journal of Biotechnology, 9, 2633-2639.

[39] Mujaju, C. and Chakuya, E. (2008) Morphological Variation of Sorghum Landrace Accessions On-Farm in Semi-Arid Areas of Zimbabwe. International Journal of Botany, 4, 376-382. http://dx.doi.org/10.3923/ijb.2008.376.382

[40] Ali, M.A., Jabran, K., Awan, S.I., Abbas, A., Zulkiffal, M., Acet, T., Farooq, J. and Rehman, A. (2011) Morpho-Physiological Diversity and Its Implications for Improving Drought Tolerance in Grain Sorghum at Different Growth Stages. Australian Journal of Crop Science, 5, 311-320.

[41] Ayana, A. and Bekele, E. (1999) Multivariate Analysis of Sorghum (Sorghum bicolour (L.) Moench) Germplasm from Ethiopia and Eritrea. Genet Resource Crop Evolution, 46, 273-284. http://dx.doi.org/10.1023/A:1008657120946

[42] Bucheyekei, T.L., Gwanama, C., Mgonja, M., Chisi, M., Folkertsma, R. and Mutegi, R. (2009) Genetic Variability Characterisation of Tanzania Sorghum Landraces Based on Simple Sequence Repeats (SSRs) Molecular and Morpho- 
logical Markers. Journal of African Crop Science, 17, 71-86.

[43] Dean, R.E., Dahlberg, J.A., Hopkins, M.S., Mitchell, S.E. and Kresovich, S. (1999) Genetic Redundancy and Diversity among Sorghum Accessions in the USA National Sorghum Collection as Assessed with Simple Sequence Repeats (SSRs) Markers. Crop Science, 39, 1215-1221. http://dx.doi.org/10.2135/cropsci1999.0011183X003900040043x

[44] Ghebru, B., Schmidt, R.J. and Bennetzen, J.L. (2002) Genetic Diversity of Eritrea Sorghum Landraces Assessed with Simple Sequence Repeats (SSR) Markers. Theoretical and Applied Genetics, 105, 229-236. http://dx.doi.org/10.1007/s00122-002-0929-x

[45] Geleta, N. and Labuschagne, M.T. (2005) Qualitative Traits Variation in Sorghum (Sorghum bicolour (L.) Moench) Germplasm from Eastern Highlands of Ethiopia. Biodiversity and Conservation, 14, 3055-3064. http://dx.doi.org/10.1007/s10531-004-0315-X

[46] Teshome, A., Baum, B.R., Fahrig, L., Torrance, J.K., Arnason, T.J. and Lambert, J.D. (1997) Sorghum (Sorghum bicolour L.) Moench] Landrace Variation and Classification in North Shewa and South Welo, Ethiopia. Euphytica, 97, 255-263. http://dx.doi.org/10.1023/A:1003074008785 